\title{
Grand-multiparity: Is it still an obstetric risk?
}

\author{
Adeola F. Afolabi, Adewale S. Adeyemi* \\ Department of Obstetrics and Gynaecology, College of Health Sciences, Ladoke Akintola University of Technology, Osogbo, \\ Nigeria \\ Email: ${ }^{\text {waleadeyemi2004@gmail.com }}$
}

Received 16 April 2013; revised 17 May 2013; accepted 26 May 2013

Copyright (C) 2013 Adeola F. Afolabi, Adewale S. Adeyemi. This is an open access article distributed under the Creative Commons Attribution License, which permits unrestricted use, distribution, and reproduction in any medium, provided the original work is properly cited.

\section{ABSTRACT}

Background: Grand-multiparity has been known to be an obstetric risk because of the documented complications associated with the condition, and it is an indication for booking in a tertiary health institution. The increase use of contraceptives and improved health care delivery is expected to reduce both the prevalence and complications of this condition. Aims and Objectives: To determine the prevalence of grandmultiparity, and if it is still associated with the previously documented complications in the obstetric population presenting at Ladoke Akintola University of Technology (LAUTECH) Teaching Hospital, Osogbo. Materials and Methods: A case controlled retrospective study of grand-multiparous women presenting in our institution over a period of ten years. All grandmultiparous women within the study period were identified from the labour ward register, and women with parity 2 - 4 served as control. Statistical analysis was done using SPSS 14. Statistical significance was set at $\mathbf{p}<0.05$. Logistic regression was done to adjust for confounding variables. Result: There were 5126 deliveries during the study period, and grand-multiparous constituted $128(2.49 \%)$ of these deliveries. Grand-multiparity was found to be associated with pre-labour rupture of membranes, $16.2 \%$ versus $4.0 \%(p=0.004)$, hypertensive diseases in pregnancy, $27.1 \%$ versus $8.1 \%(p=0.001)$, placenta praevia, $15.3 \%$ versus $4.0 \%(p=0.007)$ and other medical illnesses, $23.2 \%$ versus 6.1\% $(p=0.001)$. Post-partum haemorrhage, anaemia, puerperal sepsis and urinary tract infections were found to be significantly commoner in the grand-multiparous than in the lower parity group $(p<0.05)$. After adjusting for confounding variables grand-multiparity was still found to be significantly associated with complications at delivery $(\mathrm{OR}=2.70 ; 95 \% \mathrm{CI} 1.13-6.48)$ and poor

\footnotetext{
${ }^{*}$ Corresponding author.
}

fetal outcome (OR = 2.28; 95\% CI 1.11 - 4.65). Conclusion: Although the prevalence of grand-multiparity is on the downward trend, it still remained an obstetric risk, therefore, the importance of booking and delivery in a well-equipped facility should be emphasized among the obstetric population so as to reduce the complications that were found to be associated with the condition.

Keywords: Grand-Multiparity; High Risk Pregnancy; Obstetric Outcome

\section{INTRODUCTION}

According to the Guinness book of the world records, the greatest number of children born to one woman was 69 (16 pairs of twins, seven sets of triplets and four sets of quadruplets). The term, grand-multipara was introduced in 1934 by Solomon who called the grand-multipara the "dangerous multipara" [1]. Grand-multiparity has been differently defined in the literature. Some writers defined it as a woman with four or more parous experiences while others considered it as six or more [2]. The International Federation of Gynaecology and Obstetrics (1993) defined grand-multiparity as delivery of the fifth to ninth viable pregnancies, whereas women who are undergoing their tenth (or more) delivery are considered to be great grand-multiparous or huge grand-multip [3-6].

The incidence of grand-multiparity has decreased in most countries, mainly because it constitutes a burden to the family and state/country. In developed countries grand-multiparity is becoming rare, with an incidence of $3 \%-4 \%$ [2] of all births while in developing countries incidence of grand-multiparity is between $19.30 \%$ $33.64 \%$ [7,8]. In Nigeria for instance, the incidence of grand-multiparity is between $5.1 \%$ and $18.07 \%$ [3-6]. Grand-multiparity continued to be regarded as high risk factor and a challenge to obstetric practice in the devel- 
oping world. Grand-multiparity is one of the major contributing factor to increasing maternal mortality [9]. The list of possible hazards/complications of grand-multiparity reported in the literature is frightening, which includes gestational diabetes, pre-eclampsia, placenta praevia, multiple pregnancy, chromosomal abnormality and birth defects, malpresentations, prolonged labour, postpartum haemorrhage, uterine rupture, increased operative birth, genital sepsis and utero-vaginal prolapse [1-9]. Many studies have explored the relationship between grand-multiparity and obstetric/perinatal complications. A critical evaluation of some of these studies showed that many of the populations studied belonged to low socioeconomic status with inadequate access to modern perinatal care as well as increased maternal age. Thus the findings in developed world suggested a statistically significant higher obstetric and perinatal risk among lower multipara when compared with grand-multiparae $[3,8-$ 10]. In the same vein, studies have shown that grandmultiparity is not an independent risk factor for adverse outcome in setting of high socioeconomic status and high standard perinatal care [11-14]. In view of the foregoing, it therefore means that increased use of contraceptives and improved health care delivery is expected to reduce both the prevalence and complications of this condition [15], hence, the recent increased awareness of family planning and use of contraceptives in our environment is expected to affect grand-multiparity and its sequelae. Therefore this study is set out to determine the prevalence of grand-multiparity, and see if the condition is still an obstetric risk.

\section{MATERIALS AND METHODS}

This is a ten-year case-controlled retrospective study of grand-multiparous women presenting in our institution between 1st January 2002 and 31st December 2011. The hospital numbers of the grand-multiparous and corresponding control multiparous women were identified from the labour ward register and the case notes were retrieved from the medical record department of the hospital. Women with parity $1-4$ whose number followed that of the grand-multipara in the delivery register served as controls. There were 128 grand-multiparous women during the study period. However, 99 case notes were available for analysis, accounting for $77.34 \%$ retrieval rate, and this is a limitation of retrospective study of this nature. Information retrieved from the case notes includes: age, level of education, occupation, parity, booking status, religion, complications in pregnancy, labour and puerperium. This information is entered into SPSS work book.

Data analysis was done using SPSS 14. Data representation was done using frequencies and percentages.
Chi-square was used for test of association. Statistical significance was taken at $\mathrm{p} \leq 0.05$. Logistic regression was done to adjust for confounding variables.

\section{RESULT}

\subsection{Socio-Demographic Factors}

There were 5126 deliveries during the study period, and $128(2.49 \%)$ of these deliveries were by the grand-multiparous women. The average age of the grand-multiparous women was $36.9 \pm 3.8$ years (with a range between 30 and 47), and that of matched multiparous control group was $28.7 \pm 5.02$ years (with a range between 18 and 39 years), which is statistically significant $(\mathrm{p}=$ 0.001 ). The parity of grand-multipara ranged between 5 and 8 . The number of living children of grand-multiparous group was between 1 and 7 with a mean of $4.33 \pm$ 1.25 while that of control was between 0 and 4 with a mean of $1.20 \pm 1.26$. Women with no formal education and those with only primary education level were more in the case than the control, $36(36.4 \%)$ versus 20 $(20.20 \%)$. Sixty one $(61.6 \%)$ of the cases were Muslims and $38(38.4 \%)$ were Christians, while $37(37.4 \%)$ of the control were Muslims and 62 (62.6\%) were Christians. Those that were booked were in the minority among the grand-multipara $28(28.3 \%)$, whereas most of the controls were booked $60(60.6 \%)$ (Table 1).

\subsection{Antenatal Outcome}

Grand-multiparous women were more likely to develop pre-labour rupture of fetal membranes, $16(16.2 \%)$ versus $4(4.0 \%), \mathrm{p}=0.004$; hypertensive diseases in pregnancy, $26(26.3 \%)$ versus $8(8.1 \%), p=0.001$; placenta praevia, $15(15.3 \%)$ versus $4(4.0 \%), \mathrm{p}=0.007$ and other medical illnesses, $23(23.2 \%)$ versus $6(6.1 \%), p=0.001$ (Table 2).

\subsection{Intrapartum Events}

The average length of labour among the case was $6.95 \pm$ 4.17 , and $11.33 \pm 8.96$ hours among the control; 43 (43.4\%) of grand-multiparous women had normal length of labour while $29(29.3 \%)$ of control had normal length of labour, which was statistically significant $(\mathrm{p}=0.001)$. Sixty-five $(65.7 \%)$ of the case, and $76(76.8 \%)$ of the control had spontaneous vaginal delivery, while 31 $(31.3 \%)$ of the case, and $22(22.2 \%)$ of the control had caesarean section; therefore there was no statistically significant difference in the prevalence of normal deliveries and cesarean sections in the two groups $(p=0.184)$ (Table 3).

Bilateral tubal ligation during caesarean section was significantly commonly performed in the case than the control $(\mathrm{p}=0.009)$. 
Table 1. Socio-demographic status of subjects.

\begin{tabular}{|c|c|c|c|}
\hline Variable & Case $(\%)$ & Control (\%) & $\mathrm{p}$ value \\
\hline \multicolumn{4}{|c|}{ Age group ( in years) } \\
\hline$<20$ & - & $4(4.0)$ & \multirow{4}{*}{0.001} \\
\hline $20-29$ & - & $52(52.6)$ & \\
\hline $30-39$ & $68(68.7)$ & $43(43.4)$ & \\
\hline$\geq 39$ & $31(31.3)$ & - & \\
\hline \multicolumn{4}{|l|}{ Level of education } \\
\hline None & $8(8.1)$ & $6(6.1)$ & \multirow{4}{*}{0.003} \\
\hline Primary & $28(28.3)$ & $14(14.1)$ & \\
\hline Secondary & $42(42.4)$ & $35(35.4)$ & \\
\hline Post-secondary & $21(21.2)$ & $44(44.4)$ & \\
\hline \multicolumn{4}{|l|}{ Religion } \\
\hline Islam & $61(61.6)$ & $37(37.4)$ & \multirow{2}{*}{0.001} \\
\hline Christianity & $38(38.4)$ & $62(62.6)$ & \\
\hline \multicolumn{4}{|l|}{ Booking status } \\
\hline Booked & $28(28.3)$ & $60(60.6)$ & \multirow{2}{*}{0.001} \\
\hline Unbooked & $71(71.7)$ & 39 (39.4) & \\
\hline Total & $99(100)$ & $99(100)$ & \\
\hline
\end{tabular}

Table 2. Ante-natal complications.

\begin{tabular}{cccc}
\hline Complications & Case (\%) & Control (\%) & p value \\
\hline PROM & $16(16.2)$ & $4(4.0)$ & $0.004^{*}$ \\
Malaria & $6(35.3)$ & $19(29.7)$ & 0.432 \\
Anaemia & $22(22.2)$ & $31(31.3)$ & 0.099 \\
PIH & $26(27.1)$ & $8(8.1)$ & $0.001^{*}$ \\
Placenta praevia & $15(15.3)$ & $4(4.0)$ & $0.007^{*}$ \\
Medical illness & $23(23.2)$ & $6(6.1)$ & $0.001^{*}$ \\
Congenital anomaly & $5(5.1)$ & $2(2.0)$ & 0.222 \\
\hline
\end{tabular}

Table 3. Complications in labour.

\begin{tabular}{cccc}
\hline Complications & Case (\%) & Control (\%) & p value \\
\hline Precipitate labour & $17(23.9)$ & $1(1.3)$ & 0.001 \\
Failure to progress & $10(10.4)$ & - & $0.001^{*}$ \\
Normal labour length & $43(43.4)$ & $29(29.3)$ & $0.001^{*}$ \\
Fetopelvic disproportion & $11(11.1)$ & $8(8.1)$ & 0.315 \\
Labour complication & $19(19.2)$ & $8(8.1)$ & $0.018^{*}$ \\
\hline
\end{tabular}

\subsection{Postpartum Events}

Grand-multiparous women were more likely to develop postpartum haemorrhage when compared to the multiparous control, $28(28.3 \%)$ versus $5(5.1 \%), p=0.001 \%$. Post-partum anaemia, puerperal sepsis and urinary tract infections were found to be significantly commoner in the grand-multiparous than in the lower parity group ( $p<$ 0.05) (Table 4).

\subsection{Perinatal Outcome}

Fetal distress was more likely among grand-multiparous compared to the control, $23(23.5 \%)$ versus $6(6.1 \%), p=$ 0.001 ; and their babies were more likely to have low APGAR scores 31 (31.3\%) versus $17(17.2 \%), p=0.018$ and a birth weight that is outside the normal range $(\mathrm{p}=$ 0.015) (Table 5). The mean birth weight in the case and the control was $3.15 \pm 0.79$ and $2.90 \pm 0.65$ respectively, $\mathrm{p}=0.015$. Both low birth weight and macrosomic babies were significantly higher among the case than the control, $46(46.5 \%)$ versus $33(33.3 \%), p=0.015$. Perinatal mortality was higher among the cases than control 27 (27.3\%) versus $14(14.1 \%), p=0.026$, given a perinatal mortality rate of 232 per 1000 and 91 per 1000 live births, respectively. Likewise, maternal mortality was found to be associated with grand-multipara $(5 \%, 5.1 \%)$, whereas there was no maternal death among the control during the study period, $\mathrm{p}=0.030$ (Table 5).

Table 4. Postpartum/puerperal complications.

\begin{tabular}{cccc}
\hline Complications & Case (\%) & Control (\%) & p value \\
\hline PPH & $28(28.3)$ & $5(5.1)$ & $0.001^{*}$ \\
Anaemia & $43(43.4)$ & $26(26.3)$ & $0.008^{*}$ \\
Eclampsia & $2(2.0)$ & $5(5.1)$ & 0.222 \\
Retained placenta & $6(6.1)$ & $4(4.0)$ & 0.374 \\
Puerperial sepsis & $11(11.1)$ & $1(1.0)$ & $0.001^{*}$ \\
UTI & $5(5.1)$ & - & $0.030^{*}$ \\
\hline
\end{tabular}

Table 5. Perinatal outcomes.

\begin{tabular}{cccc}
\hline Complications & Case (\%) & Control (\%) & p value \\
\hline Fetal distress & $23(23.5)$ & $6(6.1)$ & $0.001^{*}$ \\
Perinatal asphyxia & $31(31.3)$ & $17(17.2)$ & $0.018^{*}$ \\
Normal baby's weight & $53(53.5)$ & $66(66.7)$ & $0.015^{*}$ \\
SVD & $65(65.7)$ & $76(76.8)$ & 0.184 \\
SCBU admission & $22(22.2)$ & $14(14.1)$ & 0.109 \\
Live babies & $72(72.7)$ & $85(85.9)$ & $0.026^{*}$ \\
\hline
\end{tabular}


Logistic regression showed that age contributed more significantly to the hypertension noticed in the grandmultip $(\mathrm{OR}=5.93,95 \% \mathrm{CI}=0.008-0.37)$. Grand-multiparity is significantly associated with complication at delivery $(\mathrm{OR}=2.70,95 \% \mathrm{CI}=1.13-6.48)$ and poor fetal outcome $(\mathrm{OR}=2.28,95 \% \mathrm{CI}=1.11$ - 4.65) (Table 6).

\section{DISCUSSION}

The prevalence of grand-multiparity in the present study is $2.5 \%$. This is quite a lower figure than the previously reported figures from Nigeria, 5.1\% - 18.07\% [3-6]. This lower prevalence can be explained by the on-going civilization, increased uptake of family planning as well as promotion of gender equity. This shows that grand-multiparity is becoming rare in developing countries similar to what obtains in the developed countries. The mean age of the grand-multiparous group was significantly greater than that of the control, agreeing with previous findings [3-9]. Maternal age had been said to be an independent risk factor for complications in grand-multiparity [8-10], as it was found to contribute significantly to hypertensive diseases and delivery complications in this study.

Both studied groups were mostly educated (at least secondary level of education). However, those with tertiary educational status were less likely to be grand-multiparous. Grand-multiparity as shown in this study is significantly more associated with Islamic religion. This is

Table 6. Logistic regression.

\begin{tabular}{|c|c|c|c|}
\hline $\begin{array}{c}\text { Dependent } \\
\text { variables }\end{array}$ & $\begin{array}{l}\text { Independent } \\
\text { variables }\end{array}$ & Odd ratio & $\begin{array}{l}\text { Confidence } \\
\text { interval }\end{array}$ \\
\hline \multirow{4}{*}{$\begin{array}{l}\text { Hypertension in } \\
\text { pregnancy }\end{array}$} & Age groups & 5.93 & 0.008 to 0.37 \\
\hline & Booking status & 3.21 & 0.13 to 0.73 \\
\hline & Educational status & 1.04 & 0.42 to 2.20 \\
\hline & Grand-multiparity & 4.22 & 0.10 to 0.55 \\
\hline \multirow{5}{*}{$\begin{array}{l}\text { Complications } \\
\text { at delivery }\end{array}$} & Age groups & 2.68 & 1.18 to 6.09 \\
\hline & Booking status & 1.43 & 0.62 to 3.28 \\
\hline & Educational status & 0.63 & 0.27 to 1.46 \\
\hline & Grand-multiparity & 2.70 & 1.13 to 6.48 \\
\hline & Grouped length of labour & 0.56 & 0.20 to 1.51 \\
\hline \multirow{5}{*}{ Foetal outcome } & Age groups & 1.31 & 0.64 to 2.68 \\
\hline & Booking status & 5.18 & 2.18 to 12.32 \\
\hline & Educational status & 0.47 & 0.23 to 0.95 \\
\hline & Grand-multiparity & 2.28 & 1.11 to 4.65 \\
\hline & Grouped length of labour & 0.51 & 0.22 to 1.20 \\
\hline
\end{tabular}

not unexpected as previous study had shown that awareness and uptake of contraceptives were higher among Christians [16].

Focus antenatal care has recently being advocated [17] may not be applicable to grand-multiparous women as a result of the increased pregnancy risks associated with this obstetric population as documented in this, and previous studies [3-8]. This study confirmed the previous description of grand-multiparous as "dangerous, overconfident multiparous" [1], as most of the grand-multiparous women in this study were unbooked; this may be as a result of over-confidence from previous parous experiences or due to their low socio-economic status.

Pre-labour rupture of fetal membranes, hypertensive diseases in pregnancy, placenta praevia and medical illnesses were found to be commoner in the grand-multiparous, and this agreed with previous studies [3-5]. Grandmultiparity was found to be significantly associated with failure to progress, precipitate labour, and cephalo-pelvic disproportion. There was no statistical difference in the prevalence of normal deliveries and cesarean sections in the two groups, similar to previous findings [3].

Postpartum haemorrhage, postpartum anaemia, puerperal sepsis, and urinary tract infections were the postpartum complications found in the grand-multiparous population as it had been previously documented [3-6,18].

Fetal distress in labour, birth asphyxia and birth weight outside the normal range were significantly higher in grand-multiparous women, and this may explain the higher perinatal mortality found in this group.

Maternal and perinatal mortality were significantly higher among the grand-multipara, and this consistent finding of poor pregnancy outcome in the grand-multipara from developing countries and conflicting findings in the developed countries might imply good maternity care as the way forward.

\section{CONCLUSION}

Although the prevalence of grand-multiparity is on the downward trend, it still remained an obstetric risk, therefore, the importance of booking and delivery in a wellequipped facility should be emphasized among the obstetric population so as to reduce the complications that were found to be associated with the condition.

\section{REFERENCES}

[1] Solomon, B. (1934) The dangerous multipara. Lancet, 2, 8-11.

[2] Centers for Disease Control and Prevention (2004) National Center for Health Statistics: NCHS definitions. National Survey of Family Growth.

[3] Ogbe, A.E., Ogbe, B.P. and Ekwempu, C. (2010) Obstet- 
ric outcome in grand-multiparous women in Jos University Teaching Hospital. Jos Journal of Medicine, 6, 1-5.

[4] DieJomaoh, F.M.E., Omene, J.A., Omu, A.E. and Faal, M.K.B. (1985) The problems of grandmultiparity as seen at Benin Teaching Hospital, Benin-City, Nigeria. Tropical Journal of Obstetrics and Gynaecology, 5, 13-17.

[5] Eze, J.N., Okaro, J.M. and Okafor, M.H. (2006) Outcome of pregnancy in the grandmultipara in Enugu, Nigeria. Tropical Journal of Obstetrics and Gynaecology, 23, 8-11. doi:10.4314/tjog.v23i1.14555

[6] Kuti, O., Dare F.O. and Ogunniyi, S.O. (2001) Grandmultiparity: Mothers own reason for the index pregnancy. Tropical Journal of Obstetrics and Gynaecology, 18, 3133. doi:10.4314/tjog.v18i1.14447

[7] Mutihir, J.T. (2005) Obstetric outcome of the grandmultpara in Jos, Nigeria. Journal of Medicine in the Tropics, 7, 14-20.

[8] Yasir, R., Perveen, F.Z., Ali, L., Perveen, S. and Tayyab, S. (2010) Grand-multiparity still an obstetric risk for developing countries. Medical Channel, 16, 264-268.

[9] Abro, S.T., Shaikh, S., Shaikh, F.B. and Baloch, R. (2009) Obstetrical complication in grand-multiparity. Medical Channel, 15, 53-58.

[10] Kelly, A. and Gail, L. (2008) Preterm spontaneous uterine rupture in a non-labouring grand multipara: A case report. Journal of Obstetrics and Gynaecology Canada, 30, 586589.

[11] Shamshad, B. (2004) Age and parity related problems affecting outcome of labor in grand multiparous. Pakistan
Journal of Medical Sciences, 42, 179-184.

[12] Bugg, G.J., Atwal, G.S. and Marchs, M. (2002) Grandmultipara in modern setting. British Journal of Obstetrics and Gynaecology, 109, 249-253.

[13] Benecke, C., Siebert, T.I., Kruger, T.F. and Grove, D. (2005) Antepartum and intrapartum complications in grandmultiparous patients compared with multiparous patients at Tygerberg Hospital. South African Journal of Obstetrics and Gynaecology, 11, 1-3

[14] Humphrey, M.D. (2003) Is grand multiparity an independent predictor of pregnancy risk? A retrospective observational study. Medical Journal of Australia, 179, 294-296.

[15] Omole-Ohonsi, A. and Ashimi, A.O. (2011) Obstetric performance in Amino Kano. Nigerian Journal of Clinical Practice, 14, 6-9. doi:10.4103/1119-3077.79231

[16] Adeyemi, A.S., Adekanle, D.A. and Komolafe, J.O. (2008) Pattern of contraceptives choice among the married women attending the family planning clinic of a tertiary health institution. Nigerian Journal of Medicine, 17, 6770. doi:10.4314/njm.v17i1.37359

[17] Villar, J., Ba'aqeel, H., Piaqqio, G., Lumbiganon, P., MiquelBelizan, J., Farnot, U., et al. (2001) WHO antenatal care randomised controlled trial for the evaluation of a new model of routine antenatal care. Lancet, 19, 15511564.

[18] Rozina, Y., Fauzia, P., Lubna, A., Shaista, P. and Subhana, T. (2010) Grand-multiparity still an obstetric risk for developing countries. Medical Channel, 16, 265-267. 